\title{
EFFICACY OF A LEBANESE ISOLATE OF BEAUVERIA SP. FOR THE BIOCONTROL OF BEMISIA TABACI
}

\author{
Farah Baroudy, Elvis Gerges, Lucia Hanna, Hana Sobh, Nabil Nemer and Yusuf Abou-Jawdah* \\ Department of Agriculture, Faculty of Agricultural and Food Sciences, \\ American University of Beirut, Beirut, Lebanon. \\ * Corresponding Author: Yusuf Abou-Jawdah \\ abujawyf@aub.edu.lb
}

(Received 1 August 2017 - Accepted 21 December 2017)

\begin{abstract}
Farah Baroudy, Elvis Gerges, Lucia Hanna, Hana Sobh, Nabil Nemer and Yusuf Abou-Jawdah. 2018. Efficacy of a Lebanese isolate of Beauveria sp. for the biocontrol of Bemisia tabaci. Lebanese Science Journal, 19(1): 74-84.

The sweetpotato/cotton whitefly, Bemisia tabaci (Gennadius) is a major pest of several crops worldwide. In addition to the direct damage induced, it has the ability to transmit some of the most dangerous plant viruses rendering it a very critical pest. The development of whitefly resistance to several groups of pesticides forced farmers and researchers to adopt integrated pest management strategies and to look for alternative control measures. Studies using molecular markers showed the coexistence in Lebanon of two species, the "Middle East-Asia Minor 1 species" also known as biotype B and the "Mediterranean species" also known as biotype Q. In greenhouse trials, the Beauveria pseudobassiana isolated in Lebanon was found to be quite efficient for the management of B. tabaci. Sprays containing spore suspensions of $10^{7}$ spores $/ \mathrm{mL}$ caused around $75 \%$ mortality of the early growth stages: egg, crawler, second and third instar larvae. The addition of a surfactant such as corn oil improved the mortality level that reached $98 \%$ in the egg /crawler stage and $84 \%$ in the second and third instar larvae at a spore concentration as low as $10^{5}$ conidia/mL. In view of the promising results, further medium size trials under commercial greenhouse conditions are planned.
\end{abstract}

Keywords: Whitefly management, biological control, cotton whitefly, Bemisia tabaci, Beauveria sp.

\section{INTRODUCTION}

Among 1500 reported species of whiteflies (Martin and Mound, 2007), the sweet potato/cotton whitefly, Bemisia tabaci (Gennadius) (Hemiptera: Sternorrhyncha: Aleyrodoidea: Aleyrodidae) emerged as the most destructive whitefly to agriculture production. B. tabaci has been reported from all continents except Antarctica and has been listed among the "World's Worst" 100 invaders (Global Invasive Species Database, 2017). The important features that distinguish B. tabaci are: its broad host range covering more than 1000 plant species (Abd-Rabbou and Simmons, 2010), good environmental adaptation, high fecundity, high ability to disperse and rapid development of insecticide resistance. In addition to the direct damage to plants, B. tabaci transmits over 111 plant viruses (http://www.issg.org/database). Some of these viruses are considered among the most devastating viruses, belonging mainly to the genus Begomovirus (Family: Geminiviridae), as well as to other genera such as Crinivirus, Carlavirus, Closterovirus, Ipomovirus, and Torradovirus (Brown and Czosnek, 2002; Jones 2003, Hanssen et al. 2010, NavasCastillo, et al., 2011; Abrahamian and Abou- Jawdah, 2014).

http://dx.doi.org/10.22453/LSJ-019.1.074-084 National Council for Scientific Research - Lebanon 2018® lsj.cnrs.edu.lb/vol-19-no-1-2018/ 
The taxonomy of $B$. tabaci has not been yet fully elucidated, but recent studies based on sequencing of the mitochondrial cytochrome oxidase I gene (mtCOI), the most useful molecular marker for identification of whitefly species and genera (Frohlich et al., 1999), showed that B. tabaci is a complex of morphologically indistinguishable species composed of at least 24 distinct "cryptic" species. These species exhibit a wide range of variations, including "differences in virus vectoring potential, host preference and specificity, endosymbiont composition, resistance to insecticides, and reproductive incompatibility" (Perring, 2001; Boykin et al. 2007; Dinsdale et al., 2010; De Barro et al. 2011). Among these species the "Middle East-Asia Minor 1 species" also known as biotype B and the "Mediterranean species" also known as biotype Q are the most invasive (De Barro et al. 2011). During the last two decades, B. tabaci "biotype B", which is believed to have originated in the Middle East-Asia Minor, is the most widespread since it was reported in over 54 countries. While, B. tabaci "biotype Q", which originated in the Mediterranean region, has spread to at least 10 countries where it caused severe crop damage (Xie et al., 2014).

Initially, insecticide sprays were the major approach to control whiteflies, but the rapid development of resistance to pesticides and the ineffectiveness of insecticides in virus transmission reduction, forced farmers in many parts of the world to adopt integrated pest management strategies (Caballero et al., 2011; Vassiliou et al., 2011; Xie et al., 2014). In Greenhouse production, insect-proof nets, sticky yellow traps and virus tolerant/resistant varieties became an integral complement to pesticide sprays. Despite this fact, pesticide residues are still of high concern, and efficient, economically viable biological control options should be investigated. While several commercial predators, parasites and entomopathogenic fungi are commercially available for the management of whiteflies, none has been registered so far in Lebanon.

The genus Beauveria is omnipresent in the environment; it may be isolated from insect cadavers, plant debris, soil or air (Larone, 1995). Most scientific reports about control of whiteflies using entomopathogenic fungi, such as Beauveria bassiana, Verticillium lecanii, and others were conducted under laboratory conditions (Wang et al., 2004, Quesada-Moraga et al., 2006, Mascarin et al., 2013). A strain of Beauveria was isolated in Lebanon and proved effective under laboratory conditions for the management of two insect pests of forest trees, Cephalcia tannourinensis (Abdo et al., 2008) and Thaumetopoea wilkinsoni (Abou-Jawdah et al., 2008) and the pea leafminer Liriomyza huidobrensis (Noujeim et al., 2015). Molecular characterizations based on four genes showed that the Lebanese isolate is more closely related to members of Clade C than to Clades A, B, D and F (Abou Jawdah et al., 2008 and unpublished data). Clade C has been referred to as Bea. cf. bassiana (Rehner and Buckley, 2005) and more recently as Beauveria pseudobassiana (Rehner, et al., 2011) and thus is distinct from Beauveria bassiana, the most commonly reported species in the literature for the management of insect pests.

The aim of this study is to identify the predominant whitefly biotypes present in Lebanon, and to test the efficacy of local Beauveria pseudobassiana isolate to control the most prevalent biotype of this pest under greenhouse conditions.

\section{MATERIALS AND METHODS}

\section{A. Identification of Bemisia tabaci biotypes in Lebanon}

\section{Insect collection}

A preliminary survey was conducted targeting areas located in North and South of Lebanon. A total of 10 regions were surveyed extending from the village of Kfardounine in the South and reaching Amchit in the North. Adults were collected from six host plant species. Those from tomato and cucumber were collected from greenhouses, while isolates from cauliflower and eggplant were collected from open fields. Sampling points were at least $3 \mathrm{~km}$ apart. After collection, insects were either used directly or fixed in $70 \%$ ethanol and stored at $4^{\circ} \mathrm{C}$ until analysis.

\section{DNA extraction method and PCR analysis}

Frohlich et al. (1999) extraction technique was adopted for its simplicity and reliability. Total nucleic acids were extracted from individual whiteflies by placing them on the bottom of a $1.5 \mathrm{ml}$ microcentrifuge tube and grinding in $60 \mu \mathrm{l}$ of ice-cold lysis buffer $(5 \mathrm{mM}$ Tris- $\mathrm{HCl}, \mathrm{pH}$ 8.0, containing $0.5 \mathrm{mM}$ EDTA, $0.5 \%$ Nonidet P-40 and $1 \mathrm{mg} / \mathrm{ml}$ of proteinase k) with sterilized Kontes micropestles. Extracts were then incubated at $65^{\circ} \mathrm{C}$ for $15 \mathrm{~min}$ and $95^{\circ} \mathrm{C}$ for 10 min prior to centrifugation at 12,000 rpm for 6 min to pellet debris. The aqueous supernatant was used as the DNA source for polymerase chain reaction (PCR). For PCR, a primer pair that amplifies a fragment of about $850 \mathrm{bp}$ of the mitochondrial COI gene was used: C1-J 2195 (5'-TTG ATT TTTT GGT CAT CCA GAA GT-3') and L2-N-3014 (5'TCC AAT GCA CTA ATC TGC CAT ATT A-3') (Simon et al., 2003). Amplifications were performed with Icycler 
Thermocycler (Bio-Rad Laboratories, U.S.A). PCR conditions were as follows: denaturation at $95^{\circ} \mathrm{C}$ for 2 min, followed by 30 cycles of denaturation at $95^{\circ} \mathrm{C}$ for $1 \mathrm{~min}$, annealing at $52^{\circ} \mathrm{C}$ for $1 \mathrm{~min}$, extension at $72^{\circ} \mathrm{C}$ for $1 \mathrm{~min}$, and a final extension step at $72^{\circ} \mathrm{C}$ for $5 \mathrm{~min}$. Amplicons were purified and sent for sequencing at the University of Saint Joseph, Lebanon. Other amplicons from 3 samples were cloned in p-GEM-T easy vector following standard protocols, and the resulting plasmids were sent for sequencing of the inserts. Sequences were compared with the GenBank database using the software BlastN (http://www.ncbi.nim.nih.gov/BLAST/).

\section{B. Control of Bemisia tabaci using Beauveria sp.}

\section{Bemisia tabaci rearing}

Whiteflies belonging to the most prevalent biotype (biotype B) detected in the above survey were reared on radish and broccoli plants inside insect-proof cages at the American University of Beirut (AUB) greenhouse. Adults were collected and released on cucumber plants grown in pots; they were left to lay eggs for 2-3 days. The plants were shaken vigorously and removed to another insect-proof cage where they were maintained until the insects grew to the required stage.

To differentiate between the stages used in the experiment, the following descriptions were followed: $1^{\text {st }}$ stage: eggs and first instar nymphs "crawler stage"; $2^{\text {nd }}$ and $3^{\text {rd }}$ instar nymphs; and $4^{\text {th }}$ instar or the red eye pupae. The crawler stage was not targeted specifically in our trials but indirectly when dead crawlers were observed while emerging from treated eggs.

\section{Growing Beauveria inoculum}

The local Bea. pseudobassiana isolate was originally isolated from a dead larva of a cedar web-spinning sawfly, Cephalcia tannourinensis Chevin (Abdo et al., 2008). The fungus was maintained by repeated sub-culturing on potato dextrose agar (PDA) at $25^{\circ} \mathrm{C}$. For long term storage, the fungus was placed in oil slant tubes and stored at $4^{\circ} \mathrm{C}$. As preliminary preparation of the bioassay, a spore suspension of Beauveria was sprayed on whitefly larvae. When the fungal mycelia became visible, isolation was done on PDA. A single spore colony was prepared by serial dilution of spore suspensions spread on PDA. The single spore colony was cultured on PDA at a temperature around $25^{\circ} \mathrm{C}$, and sub-cultured every 2-3 weeks by simple mycelial transfer.

For bioassays, spore suspensions were prepared by adding and scraping in sterile water amended with $0.01 \%$ Tween-20 on 2-week-old Beauveria cultures. The resulting suspension was filtered through six layers of cheesecloth to eliminate mycelial fragments. The spore concentration was determined using an improved Neubauer haemocytometer. Appropriate dilutions were conducted to obtain the desired spore concentrations. To improve the efficacy of biological control by Beauveria, a $0.5 \%$ corn oil was used as adjuvant.

\section{Bioassays}

Cucumber seeds were sown in $15 \mathrm{~cm}$ diameter pots placed in an insect-proof greenhouse compartment. The seedlings were thinned to one plant per pot and when the seedlings reached 4-5 true-leaf stage, the tip was removed. Plants were artificially infested with whiteflies that laid eggs on the plant leaves. For each treatment, four cucumber plants were inoculated. Treatments were applied when a high level of whitefly eggs or the desired larval stage was observed.

Eggs and larvae were counted under the stereoscope (10-30X magnification) and each insect stage was marked with the number of insects. An average of 20 eggs or larvae per leaf, and three leaves per plant were included in the test. Each treatment was replicated on 4 cucumber plants.

\section{Treatment application and data collection}

Beauveria spore suspensions at concentrations ranging between $10^{3} \mathrm{spores} / \mathrm{ml}$ and $10^{7} \mathrm{spores} / \mathrm{ml}$ along with their respective water and adjuvant controls were sprayed using spray bottles that distributed the treatments uniformly. The insect stages were observed daily and the data on cumulative mortality were collected after 5 days of treatment application. 
For the egg stage tests, results were separated using the following observations: infected hatched eggs/crawlers, non-hatched eggs and healthy hatched eggs. For the larval stages tests, the results were separated into: healthy larvae, dead or shrinking larvae that might have turned to red.

To confirm that the death is caused by the fungus, some treated leaves were incubated at room temperature in humid chambers to favor sporulation of the fungus. To calculate the corrected mortality of the instar caused by each treatment, the Abbott formula was used (Abbot, 1925).

$$
\text { Corrected Mortality } \%=100 * 1-\left(\frac{\mathrm{n} \text { on T plant after treatment }}{\mathrm{n} \text { on Co plant after treatment }}\right)
$$

$\mathrm{n}=$ insect population, $\mathrm{T}=$ treated, $\mathrm{Co}=$ Control

\section{Statistical Analysis}

The SPSS-13 statistical package was used for data analysis. The experiment was organized in a completely randomized design with one factor (treatment). One-way analysis of variance was used to determine the significant differences between treatments and control. Where significant $F$ values were obtained, LSD Fisher test was used to compare between means at $\alpha=0.05$.

\section{RESULTS}

\section{Bemisia biotypes in Lebanon}

PCR runs using the primer pair C1-J 2195/ L2-N-3014 produced amplicons of the expected size from all the 16 samples of $B$. tabaci collected during the survey (Fig. 1). The resulting amplicons from samples I, L and $\mathrm{P}$ were purified and cloned in p-GEM T Easy vector, while the remaining samples were purified and used directly for sequencing. Restriction digestion of the cloned p-GEM T-Easy plasmid with EcoRI enzyme, confirmed the presence of the right inserts of $850 \mathrm{bp}$ (Fig. 2), and these plasmids were sent for sequencing. BIASTN analysis of the obtained sequences revealed the presence of biotypes B and Q in North and South Lebanon, and on the three surveyed crops (Table 1).

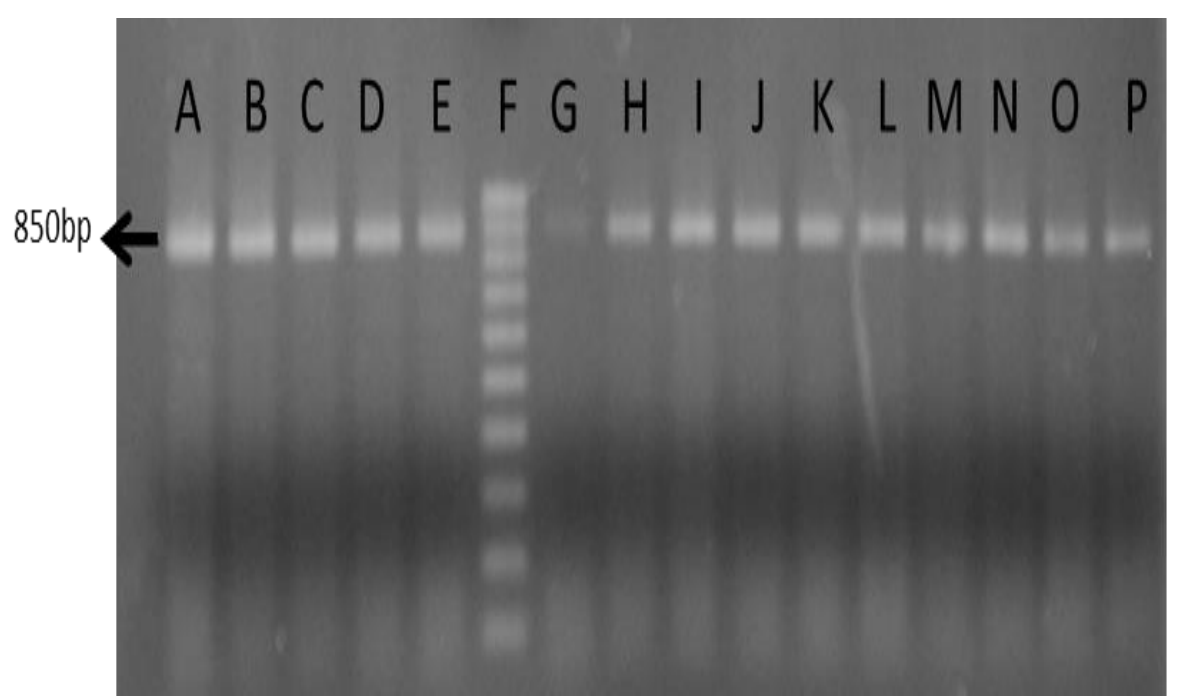

Figure 1. Agarose gel electrophoresis of PCR amplified products obtained from extracts of individual whitefly insects collected during the survey, using the primer pair C1-J 2195/ L2-N-3014. F = 100bp ladder; A: Whiteflies collected from cauliflower plants in Nehme; B-D: Whiteflies collected from cucumber plants in Bouar and Safra; E, G, H: Whitelies collected from eggplants in Bouar, Damour and Haret sakher; I-K: Whiteflies collected from tomato plants in Amchit; L-P: Whiteflies collected from tomato plants in Kfardounine, Damour, Naher el Kalb, Okaybe and American University of Beirut (AUB), respectively. 


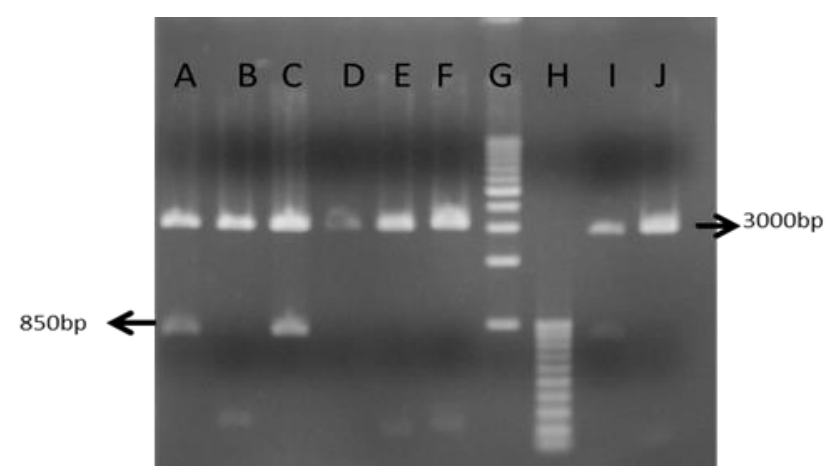

Figure 2. Agarose gel electrophoresis of cloned plasmids following digestion with EcoRI: clones A, C and I contained an insert of the expected size $(850 \mathrm{bp}) . \mathrm{G}=1 \mathrm{~Kb}$ ladder; $\mathrm{H}=100 \mathrm{bp}$ ladder.

Table1. Biotypes of Bemisia tabaci in Lebanon based on sequencing of the mtCOI gene.

\begin{tabular}{|c|c|c|c|c|c|}
\hline Crop & Location & $\begin{array}{l}\text { Samples } \\
\text { Collected } \\
\text { (No.) } \\
\end{array}$ & Biotype & $\begin{array}{l}\text { Nucleotide } \\
\text { identity \% with } \\
\text { B biotypes }\end{array}$ & $\begin{array}{l}\text { Nucleotide } \\
\text { identity \% with } \\
\text { Q biotypes }\end{array}$ \\
\hline Cauliflower & Nehme & 1 & Q & -- & $98 \%$ \\
\hline Cucumber & Bouar & 1 & $\mathrm{~B}$ & $99 \%$ & -- \\
\hline Cucumber & Safra & 2 & $\mathrm{~B}, \mathrm{Q}$ & $95 \%$ & $98 \%$ \\
\hline Eggplant & Bouar & 1 & $\mathrm{~B}$ & $97 \%$ & -- \\
\hline Eggplant & Damour & 1 & $\mathrm{Q}$ & -- & $97 \%$ \\
\hline Eggplant & Haret sakher & 1 & $\mathrm{~B}$ & $97 \%$ & - \\
\hline Tomato & Amchit & 3 & $\mathrm{Q}, \mathrm{B}, \mathrm{Q}$ & $98 \%$ & $99 \%-97 \%$ \\
\hline Tomato & Kfardounine & 2 & $\mathrm{~B}, \mathrm{~B}$ & $99 \%-98 \%$ & -- \\
\hline Tomato & Damour & 1 & $\mathrm{Q}$ & -- & $91 \% *$ \\
\hline Tomato & Naher el Kalb & 1 & $\mathrm{~B}$ & $99 \%$ & -- \\
\hline Tomato & Okaybe & 1 & $\mathrm{~B}$ & $97 \%$ & -- \\
\hline Tomato & $\mathrm{AUB}^{* *}$ & 1 & B & $96 \%$ & -- \\
\hline
\end{tabular}

* The sequence obtained was not of the desired quality.

** Experimental site, American University of Beirut, Beirut, Lebanon.

Efficacy of the local Beauveria isolate for the control of B. tabaci

Results of the three replicated trials that were conducted to evaluate the efficacy of different treatments to control various growth stages of the whitefly B. tabaci indicated significant differences in $\%$ mortality among treatments (Table 2). 
Table 2. Efficacy of treatments on Bemisia tabaci; cumulative mortalities $\mathbf{5}$ days post sprays.

\begin{tabular}{|c|c|c|c|c|}
\hline Insect Stage & $\begin{array}{l}\text { Eggs and } \\
\text { hatching }\end{array}$ & $2^{\text {nd }}$ and $3^{\text {d }}$ instar & \multicolumn{2}{|c|}{$4^{\text {th }}$ instar } \\
\hline Treatment & $\%$ Mortality & $\%$ Mortality & $\%$ Mortality & $\begin{array}{l}\% \\
\text { Corrected } \\
\text { mortality }\end{array}$ \\
\hline $10^{7}$ conidia/ml+Tween-20 & $74.42 \pm 23 b^{*}$ & $75.46( \pm 12.24) a b$ & $44.75( \pm 3.35) \mathrm{ab}$ & $38 \%$ \\
\hline $\begin{array}{l}10^{7} \text { conidia/ml }+ \text { Tween-20 } \\
+ \text { oil }^{* *}\end{array}$ & $98.25 \pm 3.94 \mathrm{a}$ & $85.17( \pm 12.28) \mathrm{a}$ & $71.93( \pm 17.75) \mathrm{a}$ & $68 \%$ \\
\hline $10^{5}$ conidia/ml+Tween-20 & $0 \mathrm{~d}$ & $65.86( \pm 4.62) \mathrm{b}$ & $31.33( \pm 21.81) \mathrm{b}$ & $23 \%$ \\
\hline $\begin{array}{l}10^{5} \text { conidia/ml }+ \text { Tween-20 + } \\
\text { oil }{ }^{* *}\end{array}$ & $98.33 \pm 2.89 \mathrm{a}$ & $84.07( \pm 17.88) \mathrm{a}$ & $69.38( \pm 22.94) \mathrm{a}$ & $66 \%$ \\
\hline $10^{3}$ conidia/ml+Tween-20 & $0 \mathrm{~d}$ & ND & ND & ND \\
\hline $10^{3}$ conidia/ml+Tween $-20+o i l * *$ & $25 \pm 0 \mathrm{~cd}$ & ND & ND & ND \\
\hline Tween- $20+$ oil $* *$ & $0 \mathrm{~d}$ & $68.3( \pm 18.36) b$ & $17( \pm 15.62) b c$ & $7 \%$ \\
\hline Tween-20 & $0 \mathrm{~d}$ & $40.33(10.6) \mathrm{bc}$ & $26.94( \pm 18.67) b c$ & $18 \%$ \\
\hline Water Control & $0 \mathrm{~d}$ & $32.1( \pm 21.53) \mathrm{c}$ & $11.15( \pm 10.99) \mathrm{c}$ & $0 \%$ \\
\hline
\end{tabular}

*Means followed by the same letter within a column are not significantly different at $\mathrm{P} \geq 0.05$.

$* *$ Corn oil at $0.5 \%$.

$* * *$ ND, Not done.

\section{Egg and crawler stage}

The highest mortalities of $98.25 \%$ and $98.33 \%$ were obtained when the highest conidial concentrations were mixed with oil: $10^{7}$ conidia $/ \mathrm{ml}+$ oil and $10^{5} \mathrm{conidia} / \mathrm{ml}+$ oil, these treatments were significantly different in $\%$ mortality from all the other treatments $(\mathrm{F}=86.221 ; \mathrm{df}=9,29 ; \mathrm{P}<0.01)$. Seventy four $\%$ mortality of eggs was achieved with a concentration of $10^{7}$ conidia/ml (with Tween-20) without corn oil as adjuvants, was significantly higher than the control and significantly lower than the treatments having the same concentration but mixed with oil (Table 2). The lower spore concentrations $\left(10^{5}\right.$ and $10^{3}$ conidia/ml $)$ didn't affect the eggs or the crawlers and didn't result in any mortality. All the other treatments: oil, Tween-20 and control showed $0 \%$ egg mortality.

Microscopic observations were recorded five days after spraying with Beauveria spore suspensions, when most whitefly eggs hatched. The fungus mycelium was observed on eggs, but mortality related to the egg stage was effectively the one observed on the crawlers leaving the eggs "ovi-larvicidal" stage (Fig. 3). 


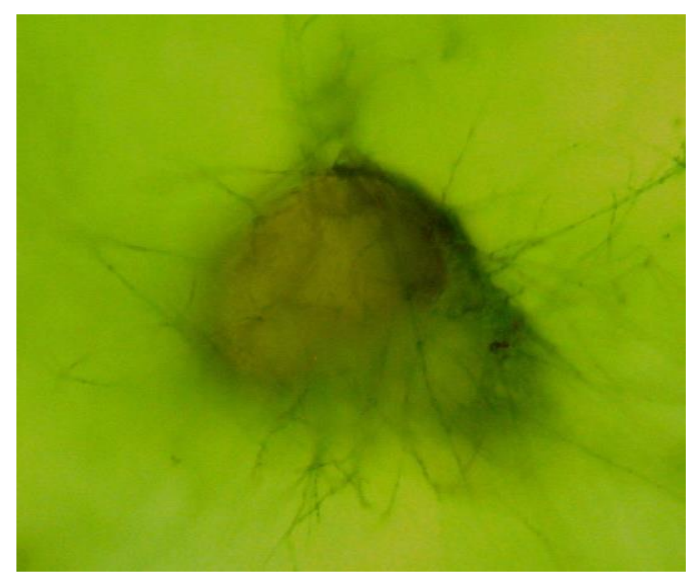

Figure 3. B. tabaci 'ovi-larvicidal" stage infected with the local Bea. pseudobassiana isolate.

\section{Second and $3^{\text {rd }}$ larval instar}

This test was also conducted in the greenhouse; with the same treatments used above, except that the lowest spore concentration was eliminated. Shrinking and red larvae were considered dead. A relatively high mortality of $32 \%$ was observed in the non-sprayed control of the $2^{\text {nd }}$ and $3^{\text {rd }}$ larval instars (Table 2). As the natural mortality of these stages reached 32\%, the corrected mortality was not applied (Abbott, 1925). The actual mortality obtained with all the treatments ranged between $65.83 \%$ and $85.16 \%$, with the highest mortalities, 84 and $85 \%$, observed when oil was added to Beauveria spore suspension of $10^{5}$ and $10^{7} \mathrm{conidia} / \mathrm{ml}$, respectively (Table 2). The latter two treatments (with oil) were significantly different in $\%$ mortality $(\mathrm{F}=6.87 ; \mathrm{df}=9,29 ; \mathrm{P}<0.05)$ from the control and Tween-20 (with oil). The $10^{7}$ conidia/ml treatment (with Tween-20 only) resulted in $75.46 \%$ mortality which was not significantly different from that of the same treatment (with oil) and the other treatment with the $10^{5}$ conidia/ml treatment (with Tween-20 plus oil) which resulted in $65.86 \%$ mortality. In addition, oil alone (with Tween-20) had an insecticidal effect similar to the $10^{5} \mathrm{spore} / \mathrm{ml}$ Beauveria (with Tween-20). In conclusion, all the treatments, except the Tween-20 treatment, increased significantly the mortality of the $2^{\text {nd }}$ and $3^{\text {rd }}$ larval instars of $B$. tabaci compared to the control.

Following data collection, some of the cucumber leaves were placed in humid chambers. Two to three days later, fungal growth appeared on the larva proving that the cause of death was the fungus. This was confirmed by microscopic mounts which showed that the observed spores belonged to Beauveria. Some of the larvae sprayed with the fungus showed a red color; these red larvae were transferred from the plant leaves grown in the greenhouse to Petri dishes containing PDA. Pure Beauveria mycelial growth appeared on these insects indicating that the fungus was the cause of death (Fig. 4 a).

\section{Fourth larval instar - the red eye stage}

Preliminary tests on the effect of Agral ${ }^{\circledR}$ on conidial germination of Beauveria showed that this adjuvant even at the highest concentration used of $600 \mathrm{~mL} / 100 \mathrm{~L}$. i.e. at double the recommended concentration had no negative effect on the germination of Beauveria spores.

The highest mortalities of the late nymphal instars were obtained with the following treatments consecutively: $10^{7}$ conidia/ml (with Tween-20) + oil, $10^{5}$ spore $/ \mathrm{ml}$ (with Tween-20) + oil, $10^{7}$ spore $/ \mathrm{ml}$ (with Tween20 ), and $10^{5}$ spore/ml (with Tween-20). Beauveria spore suspensions sprayed withTween-20 at a concentration of $10^{7}$ conidia/ml, caused a mortality of only $44.7 \%$, but when corn oil was added the mortality increased to $71.9 \%$ (Table2). Beauveria mycelial growth appeared on these insects indicating that the fungus was the cause of death (Fig. 4 b). 

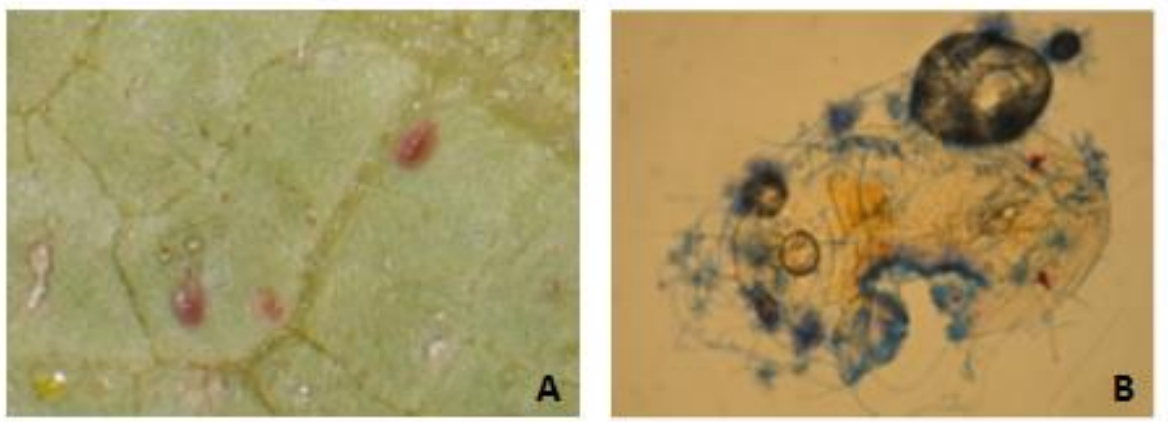

Figure 4. Symptoms caused by the local Beauveria isolate on Bemisia tabaci nymphs; a: reddish $2^{\text {nd }}$ larval instar infected by Beauveria, b: Beauveria growth on infected $4^{\text {th }}$ instar (red-eye) whitefly.

\section{DISCUSSION}

"The extensive genetic diversity of the whitefly, Bemisia tabaci, has long been recognized" and lately, suggestions have been made to replace the previous nomenclature as $B$. tabaci biotypes by over 28 new "cryptic" species named based on divergence value of over 3.5\% in the mtCOI DNA sequence (Dinsdale et al., 2010; Hu et al., 2011; Shu-sheng et. al., 2012). No previous molecular studies have been conducted to assess the Bemisia biotypes/species in Lebanon. It was commonly agreed that biotype B is present in Lebanon. This preliminary survey indicated the presence in Lebanon of two biotypes: biotypes B and Q, recently referred to as Middle East-Asia Minor 1 (MEAM1) and Mediterranean (Med), respectively. Both species prevailed along the Lebanese coastal area. The presence of the MEAM1 species (B biotype) was not surprising, since it is reported to have a cosmopolitan distribution (Perring, 2001), but this is the first report that indicated the presence of the Med species (Q biotype) in Lebanon. Biotypes B and Q are the 2 most invasive and widely distributed sub-species; both were reported in Tunisia and China (Gorsane et al., 2011; Xie et al., 2014). In fact, successful invasions (almost worldwide) of the B biotype are well documented. This biotype appears very successful in incursion, apparently as it is more insecticide resistant (Brown and Czosneck, 2002), it can fly longer distances (Blackmer et al. 1995a; Blackmer et al. 1995b) and has a higher fecundity and shorter life cycle than other tested biotypes (Bethke et al., 1991). Moreover, the B biotype has been shown to possess competitive advantages over other biotypes (Pascual and Callejas, 2004) except for biotype Q (Muniz and Nombela, 2001). Bioptype Q is the prevailing biotype in Egypt (De Barro et al., 2000), has also spread in many other countries and is becoming the predominat biotype in China with a displacement ability over the B biotype (Ahmed et al., 2009, Xie et al., 2014), because it possesses greater resistance to many insecticides than biotype B in many countries (Dennehy et al., 2005; Horowitz et al., 2005). Since Biotype B has a world-wide distribution, research focused on its control using a local isolate of an entomopathogenic fungus that proved its efficacy on other insect pests (Abdo et al., 2008; Abou-Jawdah et al., 2008; Noujeim et al., 2015).

Thus, the Lebanese Bea. pseudobassiana isolate was effective in the control of B. tabaci on all growth stages tested. However, the most effective control was obtained at the early growth stages, the eggs and crawler stages, in which the mortality reached $98.3 \%$ when a concentration of Beauveria as low as $10^{5}$ conidia/ml was mixed with corn oil. In other studies using some isolates of Bea. bassiana mixed with neem oil, just $29.5 \%$ B. tabaci eggs mortality was achieved (Islam et al., 2010). Mascarin et al. (2013) also reported a very low susceptibility of $B$. tabaci eggs towards Bea. bassiana isolates. Therefore, the high mortality of the insect early growth stages in our study show that the local Bea. pseudobassiana isolate has a higher efficacy than previously reported Beauveria bassiana isolates, and that the added oil to the spray mixture seems to improve adherence of Beauveria spores to the eggs which get infected and infect the delicate newly hatching crawlers while emerging from the eggs.

As for the $2^{\text {nd }}$ and $3^{\text {rd }}$ instars of $B$. tabaci, the $10^{7}$ and $10^{5}$ spores $/ \mathrm{ml}$ (with Tween-20) of Beauveria treatments also caused high mortality to these immature instars of 75.46 and $65.86 \%$, respectively. On the other hand, an experiment covering $25 \mathrm{Bea}$. bassiana isolates (Quesada-Moraga et al., 2006) showed that the mortality of these stages ranged from 3 to $85 \%$ when using a spore concentration similar to our study. However, the highest efficacy reported in the latter experiment may be explained by the fact that it was conducted in the laboratory with the spore suspension added by leaf dipping followed by incubation at humidity close to $100 \%$. Whereas in our study, the experiment was conducted under greenhouse conditions and the mortality reached $85 \%$ when corn oil was added to the spray suspension. Mascarin et al. (2013) also found that Bea. bassiana isolates were virulent against whiteflies larvae, providing $>70 \%$ mortality of the $2^{\text {nd }}$ instar larvae with a $\mathrm{LT}_{50}<4$ days. It is worth mentioning that in this study, during 
the $2^{\text {nd }}$ and $3^{\text {rd }}$ instar nymphs experiment, a high mortality of $32 \%$ was observed in the control treatment. However, this is in agreement with the expected natural mortality rate of these life stages. Knowing that Naranjo et al. (2004) showed that whiteflies $2^{\text {nd }}$ and $3^{\text {rd }}$ nymphal instars usually show about $15 \%$ mortality for each stage caused by environmental factors, parasites, predators, and other factors; therefore, normally at these stages mortality might reach around $30 \%$.

The fourth larval stage of $B$. tabaci was the least susceptible to Beauveria treatments with mortalities ranging from $31.3 \%$ for a spray of conidial suspension of $10^{5}$ conidia/mL (with Tween-20) to $71.9 \%$ when $10^{7}$ conidia/mL were mixed with Tween 20 and corn oil. These results are in line with those previously reported for Bea. bassiana against second and third instar whiteflies that were found to be the most susceptible larval stages. The low mortality rates observed on the fourth larval stage were explained by the toxic or inhibitory effects of whitefly cuticular lipids on conidia of Bea. bassiana, as the concentration of these lipids increases when the whiteflies advance in their larval stages growth (James et al., 2003). Corn oil enhanced the efficacy of the entomopathgenic fungus probably by improving the adherence of conidia to the host and possibly by physically harming the insects and predisposing them to the fungal infection.

The efficacy of the tested Lebanese Bea. pseudobassiana isolate in our study, was further confirmed in spring 2016 in a single span greenhouse equipped with insect-proof nets and planted with cucumbers. Normally, during this season most greenhouse farmers apply insecticide sprays every 7-14 days to maintain low whitefly pressure. In the latter trial, no insecticides were used and whitefly population was maintained at a low level just by application of three sprays of the local isolate (data not reported, unreplicated trial).

In conclusion, Bemisia Meam1 and Med species (biotypes B and Q) coexist in Lebanon and the Lebanese Bea. pseudobassiana isolate is taxonomically distinct from the Bea. bassiana isolates most often reported in the literature. The Lebanese isolate seems to be very promising for the management of B. tabaci biotype B and may play an important role in integrated pest management in greenhouse production. Large scale trials are further planned.

\section{ACKNOWLEDGEMENTS}

This work was partially supported by AUB, University Research Board (URB) and the Lebanese National Council for Scientific Research (CNRS).

\section{REFERENCES}

Abbott, W.S. 1925. A method of conputing the effectiveness of an insecticide. Journal of Economic Entomology, 18: 256-257.

Abdo, C., Nemer, N., Nemer, G., Abou-Jawdah, Y., Atamian, H., and Kawar, N. 2008. Isolation of Beauveria species from Lebanon and evaluation of its efficacy for biocontrol of the cedar web-spinning sawfly, Cephalcia tannourinensis. BioControl, 53: 341-352.

Abd-Rabou, S. and Simmons, A.M. 2010. Survey of reproductive host plants of Bemisia tabaci (Hemiptera: Aleyrodidae) in Egypt, including new host records. Entomologica News, 121: 456-65.

Abou-Jawdah, Y., Atamian, H., Nemer, G., Kfoury, L., Choukrallah, N., Hanna, L. and Nemer N. 2008. Efficacy and molecular studies of a Lebanese isolate of Beauveria for the biocontrol of Thaumetopoea wilkinsoni (Lepidoptera: Thaumetopoeidae). Biocontrol Science \& Technology, 18(6): 581-589.

Abrahamian, P. and Abou-Jawdah, Y. 2014. Whitefly-transmitted criniviruses of cucurbits: current status and future prospects. Indian Journal of Virology 25: 26-38. (DOI 10.1007/s13337-013-0173-9). Published online: October 27, 2013.

Ahmed, M. Z., Shatters, R. G., Ren, S.-X., Jin, G.-H., Mandour, N. S. and Qiu, B.-L. 2009. Genetic distinctions among the Mediterranean and Chinese populations of Bemisia tabaci Q biotype and their endosymbiont Wolbachia populations. Journal of Applied Entomology, 133: 733-741. doi: 10.1111/j.14390418.2009.01442.x

Bethke, J.A., Paine, T.D. and Nuessly, G.S.1991. Comparative biology, morphometrics and development of two populations of Bemisia tabaci (Hom.: Aleyrodidae) on cotton and poinsettia. Annals of the Entomological Society of America, 84: 407-411.

Blackmer, J. L., Byrne, D. N., and Tu, Z. 1995a. Behavioral, morphological, and physiological traits associated with migratory Bemisia tabaci (Homoptera: Aleyrodidae). Journal of Insect Behavior, 8: 251-267.

Blackmer, J. L., Lindley, V. A., and Byrne, D. N. 1995b. Histological examination of flight muscle development and breakdown in Bemisia tabaci (Homoptera: Aleyrodidae): relationship to age and flight behavior. Journal of Morphology, 226: 213-221. 
Boykin, L.M, Shatters, R.G., Rosell, R.C., McKenzie, C.L., Bagnall, R.A., De Barro, P. and Frohlich, D.R. 2007. Global relationships of Bemisia tabaci (Hemiptera: Aleyrodidae) revealed using Bayesian analysis of mitochondrial COI DNA sequences. Molecular Phylogenetics and Evolution, 44: 1306-1319.

Brown, J. and Czosnek, H. 2002. Whitefly transmission of plant viruses. Advances in Botanical Research, 36: 65100.

Caballero, R., Cyman, S. and Schuster, D. J. 2011. Monitoring insecticide resistance in biotype B of Bemisia tabaci (Hemiptera: Aleyrodidae) in Florida. Florida Entomologist, 96(4): 1243-1256.

De Barro, P. J., Driver, F., Trueman, J.W.H. and Curran, J. 2000. Phylogenetic relationships of world populations of Bemisia tabaci (Gennadius) using ribosomal ITS1. Molecular Phylogenetics and Evolution, 16: 29-36.

De Barro, P.J., Liu, S.S., Boykin, L.M. and Dinsdale, B., 2011. Bemisia tabaci: a statement of species status. Annual Review of Entomology, 56: 1-19.

Dennehy, T. J., Degain, B. A., Harpold, V. S., Brown, J. K., Morin, S., Fabrick, J. A., Byrne, F. J., and Nichols, R. L. 2005. New challenges to management of whitefly resistance to insecticides in Arizona, p. 31 In University of Arizona Cooperative Extension, Vegetable Report. http://cals.arizona.edu/pubs/crops/az1382/az1382_2.pdf).

Dinsdale, A., Cook, L., Riginos, C., Buckley, Y.M. and de Barro, P. J. 2010. Refined global analysis of Bemisia tabaci (Hemiptera: Sternorrhyncha: Aleyrodoidea: Aleyrodidae) mitochondrial cytochrome oxidase 1 to identify species level genetic boundaries. Annals of the Entomological Society of America, 103: 196-208.

Frohlich, D. R., Torres-Jerez, I., Bedford, I. D., Markham, P. G. and Brown, J. K. 1999. A phylogeographical analysis of the Bemisia tabaci species complex based on mitochondrial DNA markers. Molecular Entomology, 8: 1683-1691.

Global Invasive Species Database. 2017. Species profile: Bemisia tabaci. Downloaded from http://www.iucngisd.org/gisd/species.php?sc=106 on 12-10-2017.

Gorsane, F., Ben Halima, A., Ben Khalifa, M., Bel-Kadhi, M. S. and Fakhfakh, H. 2011. Molecular characterization of Bemisia tabaci populations in Tunisia: genetic structure and evidence for multiple acquisitions of secondary symbionts. Environmental Entomology, 40(4): 809-817.

Hanssen, I.M., Lapidot, M. and Thomma, B. P. 2010. Emerging viral diseases of tomato crops. Molecular Plant Microbe Interactions, 23: 539-548.

Horowitz, A.R., Kontsedalov, S., Khasdan, V, and Ishaaya, I. 2005. Biotypes B and Q of Bemisia tabaci and their relevance to neonicotinoid and pyriproxyfen resistance. Archives of Insect Biochemistry and Physiology, 58: 216-225.

Hu, J., De Barro, P. J., Zhao, H., Nardi, F., Wang, J. and Liu S. S. 2011. An extensive field survey combined with a phylogenetic analysis reveals rapid and widespread invasion of two alien whiteflies in China. PLoS ONE, 6:e16061.

Islam, M. T., Castle, S. J., Ren, S. 2010. Compatibility of the insect pathogenic fungus Beauveria bassiana with neem against sweetpotato whitefly, Bemisia tabaci, on eggplant. Entomologia Experimentalis et Applicata, 134: 28-34.

James, R., Bucknerb, J. and Freemanc, T. 2003. Cuticular lipids and silverleaf whitefly stage affect conidial germination of Beauveria bassiana and Paecilomyces fumosoroseus. Journal of Invertebrate Pathology, 84(2): 67-74.

Jones, D.R. 2003. Plant viruses transmitted by whiteflies. European Journal of Plant Pathology, 109: 195-219.

Larone, DH. 1995. Medically important fungi: a guide to identification. Elsevier, New York. 274 pp.

Martin, J.H. and Mound, L. 2007. An annotated check list of the world's whiteflies (Insecta: Hemiptera: Aleyrodidae). Zootaxa, 1492: 1-84.

Mascarin, G. M., Kobori, N. N., Quintela, E. D. and Delalibera, Jr. I., 2013. The virulence of entomopathogenic fungi against Bemisia tabaci biotype B (Hemiptera: Aleyrodidae) and their conidial production using solid substrate fermentation. Biological Control, 66: 209-18.

Muniz, M. and Nombela, G. 2001. Differential variation in development of the B- and Q-biotypes of Bemisia tabaci (Homoptera : Aleyrodidae) on sweet pepper at constant temperatures. Environmental Entomology, 30: 720-727.

Naranjo, S. E., Cañas, L. A., and Ellsworth, P. C. 2004. Mortality factors affecting populations of sweetpotato whitefly, Bemisia tabaci, in a multi-crop system. Horticultura internacional, 43: 14-21.

Navas-Castillo, J., Fiallo-Olive, E. and Sánchez-Campos, S. 2011. Emerging virus diseases transmitted by whiteflies. Annual Review of Phytopathology, 49: 219-248.

Noujeim, E., Sakr, J., El Sayegh, D. and Nemer, N. 2015. In Vitro susceptibility of the pea leafminer, Liriomyza huidobrensis pupae to enthomopathogenic Heterorhabditis indica and Beauveria bassiana. Lebanese Science Journal, 16(2): 19-26.

Pascual, S. and Callejas, C. 2004. Intra- and interspecific competition between biotypes B and Q of Bemisia tabaci (Hemiptera:Aleyrodidae) from Spain. Bulletin of Entomological Research, 4: 369-375. 
Perring, T. M. 2001. The Bemisia tabaci species complex. Crop Protection, 20: 725-737.

Quesada-Moraga, E., Maranhao, Ea.A., Valverde-García, P. and Santiago-Álvarez, C. 2006. Selection of Beauveria bassiana isolates for control of the whiteflies Bemisia tabaci and Trialeurodes vaporariorum on the basis of their virulence, thermal requirements, and toxicogenic activity. Biological Control, 36: 274-87.

Rehner, S. A., and Buckley, E. 2005. A Beauveria phylogeny inferred from nuclear ITS and EF1- $\alpha$ sequences: evidence for cryptic diversification and links to Cordyceps teleomorphs. Mycologia, 97(1): 84-98.

Rehner, S. A., Minnis, A. M., Sung, G. H., Luangsa-ard, J. J., Devotto, L., and Humber, R. A. 2011. Phylogeny and systematics of the anamorphic, entomopathogenic genus Beauveria. Mycologia, 103(5): 1055-1073.

Shu-sheng, L., Colvin, J., and De Barro, P.J. 2012. Species concepts as applied to the whitefly Bemisia tabaci systematics: how many species are there? Journal of Integrative Agriculture 11: 176-186.

Simón, B., Cenis, J.L., Demichelis, S., Rapisarda, Caciagli, C.P., and Bosco, D. 2003. Survey of Bemisia tabaci (Hemiptera: Aleyrodidae) biotypes in Italy with the description of a new biotype (T) from Euphorbia characias. Bulletin of Entomological Research, 93: 259-264.

Vassiliou, V., Emmanouilidou, M., Perrakis, A., Morou, E., Vontas, J., Tsagkarakou, A. and Roditakis, E. 2011. Insecticide resistance in Bemisia tabaci from Cyprus. Insect Science, 18: 30-39.

Wang, L., Huang, J., You, M. and Liu, B., 2004. Time-dose-mortality modelling and virulence indices for six strains of Verticillium lecanii against sweetpotato whitefly, Bemisia tabaci (Gennadius). Journal of Applied Entomology, 128: 494-500.

Xie, W., Liu, Y, Wang, S.L., Wu, Q.J., Pan, H.P. and Zhang,Y. J. 2014. Sensitivity of the whitefly Bemisia tabaci to several new insecticides in China: effects of insecticide type and whitefly species, strain, and stage. Journal of Insect Science 14: 1-7. Article 261. DOI 10.1093/jisesa/ieu123. 